\title{
Estratégias de polidez em momentos de dissensão: análise de uma interação entre estudantes brasileiros e alemães
}

Politeness Strategies at Dissent Moments: an Analysis of an Interaction Between Brazilian and German Learners

\author{
Ulrike Agathe Schröder \\ Universidade Federal de Minas Gerais \\ Carolina de Viterbo Lage ${ }^{1}$ \\ Universidade Federal de Minas Gerais
}

\section{Resumo}

Estudos sobre estilos comunicativos em culturas distintas permitem a constatação da existência de diferentes padróes comunicativos para diversas situações de interação. Se isso é perceptível em análises contrastivas de grupos culturais, a questão que surge é como tais padrôes distintos e, junto deles, os panos de fundo culturais por trás podem levar a conflitos em situações de comunicação intercultural. Neste trabalho analisamos justamente tais situações de conflito com base na filmagem de uma interação entre quatro brasileiros e quatro alemães. Como pressupostos teóricos se recorre a uma perspectiva construtivista da comunicação e a teorias pragmáticas que analisam estratégias interpessoais de trabalho da face e de polidez.

\section{Palavras-chave}

Comunicação intercultural, dissensão, trabalho da face, polidez 


\section{Abstract}

A series of studies about communicative styles in different cultures has revealed the existence of a certain diversity of communication patterns related to a variety of interactional situations. Therefore, once we are able to state those divergences with regard to cultural groups, we could then ask how these different patterns and cultural backgrounds might lead to conflicts in intercultural communication. In this paper, based on a videotaped interaction between four Brazilians and four Germans, we draw our attention towards such situations of conflict. As for the theoretical background of the research, we rely on a constructivist perspective on communication, as well as on pragmatic theories about facework strategies and politeness.

\section{Keywords}

Intercultural communication, dissent, face-work , politeness 


\section{Introdução}

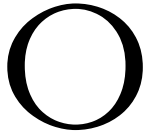

pondo-se ao modelo clássico da transmissão da informação, o comunicólogo Gerold Ungeheuer (1987) introduz um modelo construtivista para explicar o processo da comunicação, importante principalmente pela sua perspectiva interacionista e pela importância dada ao ouvinte. Ungeheuer parte da pressuposição de que os seres humanos se caracterizam por um dualismo antropológico: por um lado, eles realizam ações interiores, que compreendem percepções, sentimentos, conhecimentos, etc. e podem ser experimentadas apenas subjetivamente. Por outro lado, realizam ações exteriores, que são também acessíveis ao interlocutor. $\mathrm{O}$ que acontece no processo da comunicação é uma transformação de ações interiores em ações exteriores, $o$ que já per se apresenta um potencial de falha. Ora, agora cabe ao ouvinte a transformação da ação exterior em uma ação interior, ou seja, interpretar hipoteticamente o que foi ouvido de acordo com sua própria 'teoria individual sobre o mundo' (UNGEHEUER, 1987, p. 308) que se baseia nas experiências que o ouvinte teve no decorrer da sua vida. Diferentemente da visão linear da comunicação, neste modelo o ouvinte não é mais visto como recipiente passivo de mensagens, mas sim como construtor da mensagem.

Se já em nossa própria comunidade de fala experimentamos a inconstância do processo de entendimento por meio de assimetrias individuais com relação à 'teoria individual sobre o mundo', essa incerteza aumenta ainda mais assim que uma ação comunicativa entra no contexto de uma cultura experimentada como alheia, onde as assimetrias são potencialmente maiores. Por conseguinte, a reciprocidade das perspectivas que, mesmo nunca garantida, ainda é pressuposta tacitamente na própria cultura, é afetada agora de modo mais marcante. Isso significa que o falante tem uma dupla tarefa: ele não apenas tem que transformar as experiências interiores em ações exteriores, mas também adequar as ações exteriores ao contexto da outra cultura, o que torna a comunicação ainda mais susceptível à falibilidade. No momento em que a ação do outro não puder ser 
interpretada de acordo com a própria teoria de mundo por não corresponder com os próprios modos de pensar, falar e atuar, os participantes da comunicação enfrentam-se com incompreensibilidade, distância e dúvidas em relação à própria competência ou à do outro (SCHRÖDER, 2008).

O objetivo do grupo de pesquisa 'Comunicação Intercultural entre Brasileiros e Alemães', inaugurado em 2009, ${ }^{2}$ é descobrir como esse processo se constitui em uma situação concreta. Para tal, filmamos, até hoje, duas interações: a primeira composta por quatro brasileiros e quatro alemães; a segunda composta por quatro brasileiras e quatro alemãs. No estudo apresentado aqui, pretendemos focalizar as estratégias de polidez observadas durante a primeira interação, investigando se os momentos de potenciais conflitos revelam estilos comunicativos distintos, relacionados ao respectivo pano de fundo cultural dos participantes. Apesar da possível influência de fatores como características individuais dos participantes e experiências prévias, levantamos a hipótese de que diferentes estilos comunicativos associados ao pano de fundo cultural dos participantes, assim como os diferentes pressupostos referentes à cultura de origem que eles carregam podem ser a causa dos conflitos observados.

\section{Referencial Teórico}

\subsection{Revisão da literatura}

Com o surgimento da Pragmática Intercultural e dos Estudos da Comunicação Intercultural, a partir dos anos setenta, observa-se um crescimento de estudos que tratam das diferenças entre os estilos comunicativos de grupos culturais distintos. Até hoje, são tais estudos comparativos que caraterizam o panorama nesse campo, como já consta em Clyne (1994, p. 3-4).

Quanto ao estilo alemão em oposição a outras línguas, House (2003) o compara ao norte-americano, descrevendo o estilo alemão como muito direto ou até ofensivo (HOUSE, 2003). Ela conclui que o estilo da fala alemão é mais explícito com relação ao "extent to which a message is coded unambiguously in the words that are chosen" (HOUSE, 2003, p. 49). De modo similar, Markowsky e Thomas (1995) comparam afirmações de estudantes norte-americanos, gregos e japoneses que vivem na Alemanha sobre suas impressões do estilo oral dos alemães. Nesse estudo, todos os grupos constataram que os alemães dão mais 
atenção ao conteúdo e à organização da fala do que à relação entre locutor e interlocutor. Um estudo recente de Günthner (2008) já parte de uma abordagem intercultural interacionista (CLYNE, 1994, p. 3), analisando uma conversa entre duas estudantes alemãs, uma estudante intercambista chinesa e um estudante intercambista chinês. Nas entrevistas retrospectivas, os dois chineses também caracterizaram as alemãs como "direct", "aggressive" e "rude, yes bit offensive" (GÜNTHNER, 2008, p. 208).

Apesar do número reduzido de pesquisas que abordam o estilo brasileiro em comparação com outras línguas, no que concerne à comparação com alemão, encontra-se um campo crescente: Meireles (2001) analisa as diferenças de uso da negação observada em um corpus brasileiro e um alemão, concluindo que falantes do português brasileiro usam menos elementos sintáticos negativos que desafiem a ilocução ou o valor de verdade das proposições apresentadas pelos interlocutores, o que poderia ser uma causa de conflitos interculturais quando em uma interação. Já Carvalho e Trevisan (2003) realizam entrevistas com trabalhadores brasileiros e alemães de uma multinacional, apontando para um estilo conversacional de brasileiros, que teriam maior dificuldade de dizer 'não', evitando confrontos com o interlocutor, mesmo quando discordam, sendo caracterizados como mais afetivos e brincalhões. Os alemães, em contrapartida, apresentariam um estilo mais direto e confrontativo, sendo mais objetivos e caracterizados por brasileiros como sérios e tensos (cf. CARVALHO; TREVISAN, 2003, p. 81-83). Essas observaçōes também correspondem aos resultados do estudo comparativo de Schröder $(2003 ; 2010)$ que revela que, no estilo de fala cotidiano brasileiro, as funções comunicativas que vêm mais à tona são a apelativa, a emotiva, a poética e a fática, ao passo que, no estilo alemão analisado, as funçôes referencial e metacomunicativa se destacam mais.

Nosso trabalho, por sua vez, ao abordar uma interação entre participantes das culturas brasileira e alemã, dedica-se a uma situação ainda não analisada com relação a essas duas comunidades de fala, buscando dessa forma verificar como as diferenças observadas pelos autores acima mencionados em caráter comparativo se aplicam efetivamente a uma interação intercultural.

\subsection{Estratégias de Polidez, 'Rapport Management' e Estilos Interacionais de conflito}

O referencial teórico segue principalmente a teoria da polidez de Brown e Levinson (1987), complementada pelo conceito de 'Rapport Management', 
como elaborado por Spencer-Oatey (2008), e o modelo de Ting-Toomey e Oetzel (2007), que se mostra útil para a análise das situaçôes de conflito observadas durante a interação.

Brown e Levinson (1987) se baseiam nas ideias desenvolvidas por Goffman (1967), que descreve dois tipos de comportamento que ocorrem em comunicações face a face para evitar ameaças à face do outro: 'processos de evasão' durante os quais uma pessoa tenta evitar as ameaças que possam ocorrer nos contatos, impedindo, por exemplo, temas tabus e atos de fala específicos e 'processos de correção' que são usados para compensar um dano relacionado à face de outro e que se caracterizam por rituais da afirmação e da aprovação do outro. Brown e Levinson (1987, p. 62) retomam essa dicotomia distinguindo entre 'face negativa', que seria o desejo de que as ações do participante não sejam impedidas pelos outros e 'face positiva', o desejo de que as expectativas do participante sejam compartilhadas pelos outros.

Em correspondência a isso, os autores estabelecem o conceito dos 'atos ameaçadores à face' (FTA = 'face threatening acts'), que representariam alguns tipos de ações que intrinsecamente causam dano à face do outro, na medida em que vão contra os desejos de face ('face wants') do falante ou do ouvinte. As expressões de desaprovação, contradições, críticas, dissensões, entre outras, são listadas por Brown e Levinson como alguns dos FTAs que potencialmente causam dano à face positiva do interlocutor. Dessa forma, a ocorrência de dissensão em uma interação pressuporia a utilização de meios para a preservação da face do outro, atenuando o efeito do FTA através do emprego de estratégias de polidez, da realização indireta do FTA ou mesmo da sua não realização.

A utilização ou não dessas estratégias cria diversas possibilidades de realização de um FTA, gerando classes e subclasses que podem representar um maior ou menor risco à face do outro. Se tomarmos, por exemplo, a situação em que um indivíduo precisa de uma caneta emprestada, teremos as seguintes possibilidades, adaptadas livremente de Meibauer (2008, p. 115): (1) Não arriscar nenhum FTA: olhar na própria bolsa; (2) Realizar o FTA indiretamente (off record): dizer "Esqueci minha caneta"; (3) Realizar o FTA com estratégia de polidez negativa: dizer "Com licença, você poderia me emprestar sua caneta?"; (4) Realizar o FTA com estratégia de polidez positiva: dizer "Ei, amigo, me empresta sua caneta aí!”. (5) Realizar o FTA sem estratégias de polidez (bald on record): dizer "Me dá sua caneta!". Essas possibilidades de realização de um FTA apresentam, de acordo com Brown e Levinson (1987), um risco de perda de face 
proporcional à sua realização direta. Dessa forma, a estratégia 5 (bald on record) apresentaria o maior grau de ameaça à face, enquanto as estratégias 1 e 2 apresentariam os menores riscos à face.

Apesar da importância do modelo de Brown e Levinson para os estudos de trabalho da face, ele também é alvo de muitas críticas, como em relação ao universalismo que os autores clamam para seus princípios de polidez. Esse posicionamento é criticado por autores como Wierzbicka (2003) ou Pizziconi (2009), que afirmam que esse caráter universal seria na verdade, paradoxalmente, uma visão etnocêntrica de Brown e Levinson, que analisariam as estratégias de polidez sob um ponto de vista britânico-americano.

Também é alvo de críticas a ausência de uma perspectiva interpessoal no modelo e de conceitos como a identidade social, como aponta Spencer-Oatey (2008). A autora propõe a análise de interações com base em outro modelo, denominado 'Rapport Management', que também utiliza conceitos do trabalho da face, foca-se no gerenciamento da harmonia e desarmonia nas interaçôes, envolvendo basicamente três componentes interconectados: o gerenciamento de face, o gerenciamento de direitos e deveres sociais e o gerenciamento de objetivos interacionais. Em oposição a Brown e Levinson, o modelo sugerido por SpencerOatey é mais abrangente, focalizando o nível da relação na interação como um todo e não apenas em momentos específicos.

Outro ponto abordado por Spencer-Oatey (2008) é o fato de a teoria de Brown e Levinson não englobar situações em que os participantes atacam a face do outro. De acordo com eles, "in general, people cooperate (and assume each other's cooperation) in maintaining face in interaction, such cooperation being based on the mutual vulnerability of face" (BROWN; LEVINSON, 1987, p. 61). A existência de situações em que os participantes não procuram atender aos desejos de face dos outros, porém, leva à necessidade de uma teoria que englobe esses aspectos. Nessa perspectiva, Spencer-Oatey (2008) incorpora em seu modelo o que chama de 'rapport orientation', distinguindo entre quatro diferentes tipos: a) 'rapport enhancement orientation' como desejo de fortalecer relações de harmonia entre os interlocutores, b) 'rapport maintenance orientation' como o desejo de manter ou proteger as relaçóes de harmonia entre os interlocutores, c) 'rapport neglect orientation' como a falta de interesse na qualidade das relações entre os interlocutores e, finalmente, d) 'rapport challenge orientation' como o desejo de desafiar ou prejudicar relações de harmonia entre os interlocutores. 
De modo similar, Ting-Toomey e Oetzel (2007) desenvolvem um modelo situacional para a análise de conflitos interculturais, do qual se destaca para este trabalho a abordagem sobre estilos interacionais de conflitos (Conflict Interaction Styles). O estilo de conflitos de um indivíduo se associa a diversos fatores, entre os quais pode figurar o pano de fundo cultural e direcionamentos de face do indivíduo. Dependendo do nível de preocupação com a própria face (Concern for Self) ou com a face do outro (Concerns for Other), o participante de um conflito pode apresentar diferentes tipos de estilos.

Um estilo resultante de uma baixa preocupação com a própria face e com a face do outro, por exemplo, seria o Avoiding, que reflete a tendência de evitar os conflitos. Uma maior preocupação com a face do outro já indicaria o estilo Accomodation, enquanto uma maior preocupação com a própria face resultaria no estilo Domination. Os outros dois estilos, Integration e Compromising refletem respectivamente uma alta e uma média preocupação com a própria face e a face do outro (TING-TOOMEY; OETZEL, 2007, p. 127)

Um exemplo da aplicação desses conceitos, segundo Ting-Toomey e Oetzel (2007, p. 126-127), seriam estudos que revelam que culturas mais individualistas (e.g. norte-americanos) tendem a empreender um estilo interacional de conflito voltado para a proteção da própria face, como Domination, enquanto culturas mais coletivistas (e.g. japoneses) preferem um estilo voltado para a face do outro, como Avoiding e Accomodation. Ainda segundo os autores, a diferença de estilos de conflito pode gerar problemas em interaçôes interculturais, uma vez que culturas classificadas como individualistas tendem a perceber os estilos de evitação e acomodação como sinal de desengajamento e desinteresse, o que é visto de forma diferente por culturas coletivistas, que utilizam esses estilos como estratégias de manutenção da harmonia.

\section{Metodologia}

O procedimento adotado na interação filmada tem origem na sociolinguística interacional e envolve a combinação de interação simulada com instruçôes fracas para estimular a conversa entre os participantes e entrevistas retrospectivas (KASPER, 2008).

Foram selecionados quatro estudantes intercambistas alemães e quatro estudantes brasileiros de diferentes cursos para participarem de uma conversa estimulada. Como os estudantes alemães moravam no Brasil, possuindo assim conhecimentos de português e da cultura brasileira, foram selecionados 
brasileiros que possuíssem conhecimentos da língua e cultura alemãs. A interação foi realizada na Faculdade de Letras da Universidade Federal de Minas Gerais com a duração de aproximadamente duas horas. Os participantes, todos do sexo masculino, podiam conversar sobre diversos temas de forma mais ou menos livre, motivados por cartões com perguntas a serem discutidas. As perguntas eram em sua maioria de cunho pessoal ou propiciavam discussões sobre diferenças culturais entre Brasil e Alemanha, por exemplo, Onde você mora? Como você mora? Onde você gostaria de morar? O arranjo dos participantes e da gravação é ilustrado no seguinte esquema:

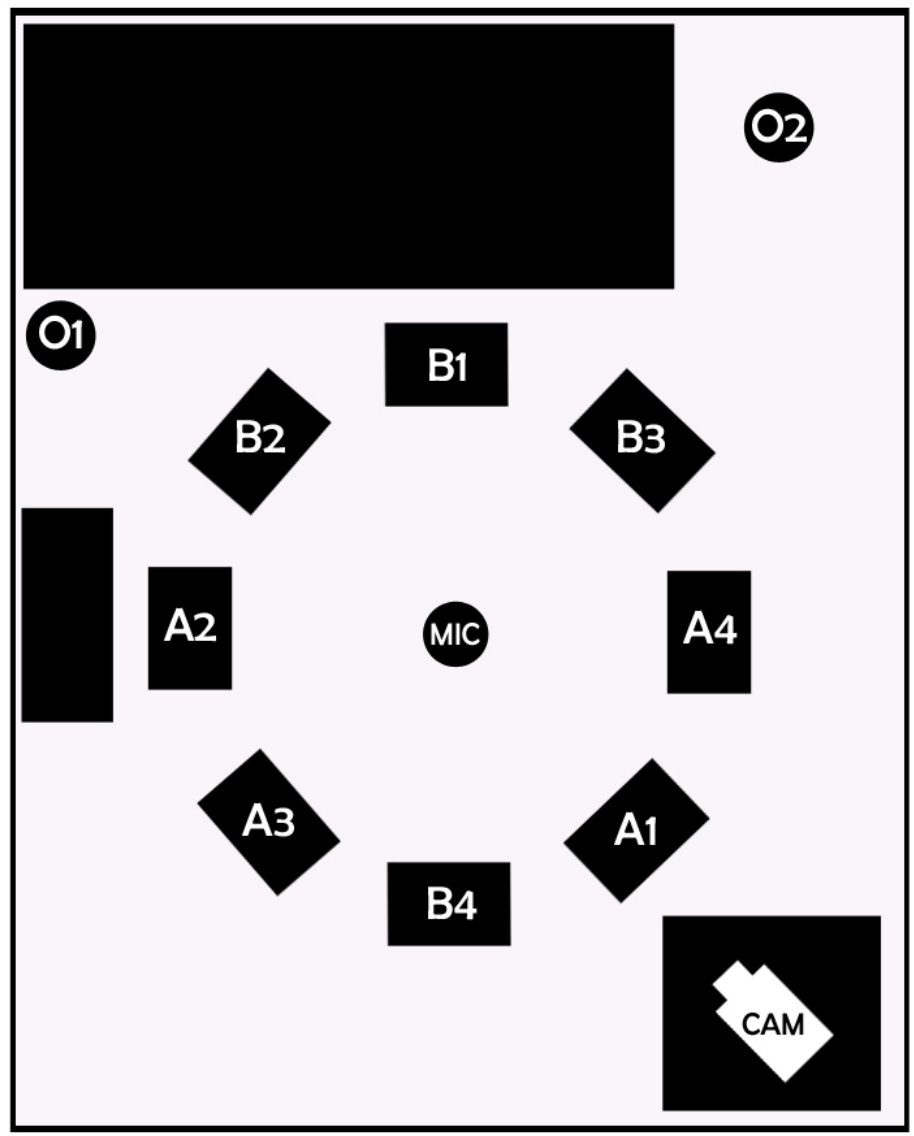

FIGURA 1: Arranjo da interação ( $\mathrm{A}=$ Alemão; $\mathrm{B}=$ Brasileiro; $\mathrm{O}=$ Organizadores $)^{3}$ 
Após a filmagem, a conversa foi transcrita, inicialmente, com base nas convençôes propostas por Dionísio (2006). Com a continuidade do trabalho no grupo de pesquisa, porém, sentiu-se a necessidade de adotar uma convenção que representasse melhor os eventos não verbais, atendendo melhor às expectativas de análise. A convenção GAT 2 (SELTING; AUER et al., 2009) foi selecionada devido às suas possibilidades de transcrição de elementos prosódicos e gestuais, além de sua grande aceitabilidade no meio acadêmico internacional. A transcrição da Interação 2 , em processo de realização, já segue essas convençōes, enquanto a transcrição da interação 1 foi posteriormente adaptada para as convenções GAT-2 $2^{4}$, que podem ser consultadas no Anexo 1 deste artigo.

Os nomes dos participantes foram substituídos na transcrição por códigos, sendo denominados por uma letra seguida de um número. Assim, os participantes alemães receberam um código com a letra $\mathrm{A}$ ( $\mathrm{A} 1, \mathrm{~A} 2, \mathrm{~A} 3, \mathrm{~A} 4)$, os participantes brasileiros com a letra $\mathrm{B}(\mathrm{B} 1, \mathrm{~B} 2, \mathrm{~B} 3, \mathrm{~B} 4)$ e os organizadores que participaram no início da interação pela letra $\mathrm{O}(\mathrm{O} 1$ e $\mathrm{O} 2)$.

Após o encontro foram realizadas entrevistas retrospectivas com os participantes, com a finalidade de coletar as impressões que eles tiveram durante a conversa. Os pesquisadores fizeram perguntas introdutórias e, em seguida, mostraram partes da filmagem para o entrevistado e perguntaram sobre momentos da interação mais específicos.

A análise da interação conta com uma parte quantitativa, que oferece um panorama com a contagem e classificação dos FTAs relacionados à dissensão, e com uma parte qualitativa, em que os momentos de dissensão são analisados de acordo com as teorias listadas na seção anterior.

\section{Análise}

\subsection{Análise quantitativa}

Após a identificação de situações de dissensão na interação, foi feita uma classificação dos FTAs de acordo com o modelo de Brown e Levinson (1987). A seguir, vê-se uma tabela com os resultados da análise: 
TABELA 1

Contagem das expressões de dissensão e classificação

\begin{tabular}{|c|c|c|c|c|c|c|c|c|c|}
\hline \multirow[b]{2}{*}{ Alemão $\rightarrow$ Alemão } & \multicolumn{2}{|c|}{ Offrecord } & \multicolumn{2}{|c|}{ Polidez negativa } & \multicolumn{2}{|c|}{ Polidez positiva } & \multicolumn{2}{|c|}{ Bald on record } & \multirow{2}{*}{$\begin{array}{r}\text { Total } \\
37 \\
\end{array}$} \\
\hline & 4 & $10,81 \%^{5}$ & 14 & $37,84 \%$ & 11 & $29,73 \%$ & 8 & $21,62 \%$ & \\
\hline Alemão $\rightarrow$ Brasileiro & 7 & $18,92 \%$ & 13 & $35,14 \%$ & 5 & $13,51 \%$ & 12 & $32,43 \%$ & 37 \\
\hline Brasileiro $\rightarrow$ Alemão & 2 & $9,09 \%$ & 7 & $31,82 \%$ & 8 & $36,36 \%$ & 5 & $22,73 \%$ & 22 \\
\hline Brasileiro $\rightarrow$ Brasileiro & 1 & $6,67 \%$ & 6 & $40,00 \%$ & 6 & $40,00 \%$ & 2 & $13,33 \%$ & 15 \\
\hline Total Alemão & 11 & $14,86 \%$ & 27 & $36,49 \%$ & 16 & $21,62 \%$ & 20 & $27,03 \%$ & 74 \\
\hline Total Brasileiro & 3 & $8,11 \%$ & 13 & $35,14 \%$ & 14 & $37,84 \%$ & 7 & $18,92 \%$ & 37 \\
\hline Total & 14 & $12,61 \%$ & 40 & $36,04 \%$ & 30 & $27,03 \%$ & 27 & $24,32 \%$ & 111 \\
\hline
\end{tabular}

Essa tabela apresenta um panorama da interação e das ocorrências de dissensão classificadas de acordo com o modelo de Brown e Levinson (1987). Observa-se em um primeiro momento uma realização muito maior de dissensóes por parte dos alemães (74), exatamente o dobro da realização por brasileiros (37), o que poderia indicar uma propensão maior por parte dos alemães à dissensão. Entretanto, os números elevados de expressões de dissensão por parte dos alemães deve-se também ao fato de eles apresentarem uma maior participação na conversa. Enquanto os alemães dominaram cerca de 870 turnos na interação, os brasileiros foram responsáveis por pouco mais de 590 turnos. Isso significa que o total de dissensões por parte dos alemães corresponde a $8,5 \%$ da sua participação na interação, enquanto o total de dissensões dos brasileiros seria equivalente a 6,3\% da participação deles. Embora aparentemente seja notada uma maior tendência dos alemães à expressão de dissensão, é necessária uma análise mais detalhada de como se dá de fato a sua realização por parte dos alemães e brasileiros.

Cabe destacar o papel que participantes específicos desempenharam na interação. $\mathrm{O}$ participante $\mathrm{A} 2$, que foi descrito por vários participantes durante as entrevistas retrospectivas como 'moderador' da conversa, foi responsável por cerca de 378 turnos e por 38 das 74 dissensões realizadas por alemães. Do lado brasileiro, a participação maior foi do participante B1, com um total de 318 turnos e 18 das 37 dissensões realizadas por brasileiros. Nota-se, dessa forma, que aos dois participantes atribui-se praticamente a metade da participação dos brasileiros e alemães na interação. A posição de A2 deve ainda ser ressaltada uma vez que ele é o participante com maior tempo de vivência no Brasil entre os alemães, tendo chegado no Brasil há oito anos, aos 16 anos. Como possuía excelente domínio da língua portuguesa e alemã, parece ser, até um certo ponto, 
não surpreendente que assumisse esse papel de moderação, o que foi reconhecido por outros participantes durante as entrevistas retrospectivas.

Quanto às manifestaçôes linguísticas dos FTAs, podemos destacar algumas estratégias abordadas por Brown e Levinson (1987) que também foram observadas durante a interação. $\mathrm{Na}$ categoria 'polidez positiva', alemães e brasileiros apresentaram estratégias como evocar acordo (issue a token agreement) e criar pontos comuns (create common points); na categoria 'polidez negativa' marcadores modalizadores delimitadores (hedges) e marcadores de atenuação e, na categoria 'bald on record', o uso de lexemas com semântica negativa e conjunções adversativas. Os participantes alemães, porém, utilizaram mais intensamente meios como ironia, perguntas retóricas e tautologias, na categoria 'off record, enquanto os brasileiros na mesma categoria preferiram utilizar sentenças vagas ou incompletas.

Para essa contagem procuramos nos ater ao modelo de Brown e Levinson (1987), o que gerou alguns problemas e dificuldades de classificação. Sendo a teoria da polidez aplicável a diversos tipos de ameaça à face, o FTA 'dissensão' não é analisado tão profundamente nesta obra, o que tornou sua classificação um pouco problemática na análise. Isso ocorreu, por exemplo, na distinção entre as categorias 'polidez positiva' e 'polidez negativa', uma vez que a amenização de um FTA de dissensão pode demonstrar uma preocupação tanto com a face negativa do interlocutor, dando-lhe liberdade de expressão de suas opiniōes, quanto com a sua face positiva, mostrando uma aceitação do interlocutor ou de sua opinião, ainda que parcialmente. Existem ainda casos em que o enunciado não aponta nenhuma marcação verbal de estratégias atenuadoras, o que levaria à classificação dele como 'bald on record'. Quando se analisa mais atentamente, porém, percebem-se marcações não verbais de atenuação, como a entonação, que na nossa análise pode indicar uma relativização da opinião, estratégia utilizada principalmente pelos brasileiros. Como no modelo de Brown e Levinson (1987) não são feitas considerações em relação a elementos não verbais, preferimos classificar os FTAs com base nas categorias providas pelos autores, discutindo posteriormente casos específicos.

Dessa forma, podemos entender a contagem apenas como um primeiro panorama da interação, apontando para a necessidade de uma análise mais detalhada da interação que leve em conta outros modelos teóricos além do modelo de Brown e Levinson (1987), como o Rapport Management de Spencer-Oatey (2008) e o modelo situacional de conflitos, de Ting-Toomey e Oetzel (2007). 


\subsection{Análise de trechos da interação}

Nesta seção serão apresentadas situaçôes de dissensão que se destacam tanto por apontar as dificuldades de classificação de acordo com o modelo de Brown e Levinson (1987) quanto pelas diferenças culturais que podem ser depreendidas através delas. Tais diferenças em alguns momentos chegam a gerar conflitos interculturais entre os participantes, o que será analisado com base nos estudos listados na seção 2 deste artigo.

Fazendo-se uma relação dos estilos comunicativos com os padrões culturais, chama a atenção um estilo utilizado pelos alemães que pode ser considerado mais direto, em concordância com estudos como o de Günthner (2008) e House (2003), quando comparado com o estilo brasileiro, mais indireto. Porém, o estilo direto alemão nem sempre é manifestado por estratégias bald on record de realização da dissensão. O maior conflito parece surgir de questionamentos dos participantes alemães, em que fica claro o posicionamento do falante. Essa estratégia pode ser observada principalmente no participante A2 e é demonstrada no seguinte trecho, em que B2 afirma achar o português antigo muito bonito, referindo-se a uma troca de cartas entre Manuel Rodrigues Lapa e Celso Cunha e A2 expressa sua dissensão:

01 A2: pois é; (.)

02 eu querialeu queria que você me explicasse um pouquinho;

03 qual que é o praZE:R, ((movimento com as mãos acompanhando ritmo da fala))

04 de ver por exemplo um português que é utilizado dessa maneira assim literá::ria-

05 com uma certa-=né?

06 com todo esse registro literário em VOLta,

$07 \quad(1.7)$

08 A2: <<levantando os ombros $>$ por que $>$ que isso invalida aquilo que é falado?

09 B2: não não invaLI:da,

10 A2: <<acc> nã_não> mas eu falo assim-

11 porque isso é bonito e o outro não é?

12 B2: sonoridade.

13 A2: sonoriDAde?

14 B2: <<afirmando com a cabeça> sonoridade.>

15 A1: mas então dá um exemplo você conhel 
16 vocês têm-

17 B2: ah:: não vou lembrar não

18 < <movimento de negação com indicador> [hahaha ]>

19 A2:

mas (porque) é interessante-

20 você liga a sonoridade a uma coisa que você $L \hat{E}$,

21 e não a alguma coisa que foi realmente falada,

22 porque você não VÊ o diálogo entre eles você vê uma

coisa escrita;

23 B1: igual latim vulgar e [latim padrão]

24 B2: [aí eu leio ] em voz alta e SINto

assim a sonoridade.

25 A2: ah você fala/você lê em voz alta-

26 [mas você LÊ. ] (.)

27 B2: [é mas é lógico que sozinho-]

28 A2: você não FALA,

29 ninguém fala assim.

30 B2: é ninguém fala;

31 ((mexe-se na cadeira para frente e para trás))

32 A2: <<rindo alto >ué mas então->

33 ((bate uma palma da mão na outra))

34 B2: mas que é bonito é-

35 ((ri)) que é bonito é;

36 A2: $\wedge$ AH:::-

37 isso é que é interessante;

38 a oralidade e a escrita.

39 uma coisa é uma coisa e outra coisa é outra coisa.

A estratégia que A2 usa aqui, fazendo perguntas insistentes que acabam por conduzir a interação ao rumo desejado, revelou-se como característica deste participante: a busca por aprofundar o assunto. Aparentemente ele não está satisfeito com respostas das quais se possa suspeitar que contenham lugares comuns (como a afirmação de que o português escrito seria melhor do que o falado, no caso do trecho apresentado). Observa-se aqui a dificuldade de classificar a estratégia realizada por A2 como 'polidez positiva', motivada pelo desejo de perguntar em vez de discordar; ou como 'off record', pois as perguntas também podem ser interpretadas como sendo retóricas e com isso, marcam uma ameaça à máxima da qualidade segundo Grice (1975). É o formato retórico - a repetição da frase colocada como pergunta - que passa a impressão de uma duplicação do sentido, 
estratégia que também é descrita por Günthner (2008, p. 211) como “rhetorical formats which take up the prior speaker's syntactic and lexical framework, negate the statement or substitute a main element of the utterance and thus highlight the polarity between the two turns." No final desse trecho, A2 traz ainda uma segunda estratégia off record, a tautologia "uma coisa é uma coisa e outra coisa é outra coisa" (linha 39), através da qual parece procurar reforçar sua opinião.

As estratégias usadas por A2 para aprofundar o assunto foram interpretadas pelos demais participantes de diferentes formas. Enquanto o participante B3 relata em entrevista retrospectiva que essa estratégia demonstrava o interesse de A2 na conversa, o que poderia ser associado ao uso da 'polidez positiva', outros participantes sentem-se incomodados com essa estratégia. B4, por exemplo, descreve a atitude de A2 como "chata" e B2, que tem sua face ameaçada no trecho analisado, relata que essa mesma atitude, percebida como "irônica" ou "debochada" o fez sentir "nervoso" e "desagradável", como se A2 quisesse "desafiar", "me testar", "invadir meu espaço". Essa interpretação da atitude de A2 poderia denotar uma ameaça à face negativa do participante, por representar uma invasão ao espaço e ao mesmo tempo uma ameaça à face positiva, devido à dissensão implícita nas perguntas retóricas. O fato de a dissensão no caso não ser expressa explicitamente faz com que essa estratégia possa ser classificada como indireta ou 'offrecord', o que foi descrito por Brown e Levinson (1987) como uma estratégia mais indireta e com menor potencial de risco à face do que as estratégias de polidez. Porém, a reação de B2 e B4 a esse comportamento indica que a estratégia pode causar um dano maior à face do interlocutor do que é possível perceber através de uma primeira classificação nos termos de Brown e Levinson (1987), levando à necessidade de uma reflexão mais profunda sobre os efeitos dessa categoria.

Diferentemente dos brasileiros, os participantes alemães não parecem ter se incomodado com as tentativas de aprofundar o assunto de A2, não expressando nenhum desconforto quanto a isso durante a interação ou durante as entrevistas retrospectivas. Isso pode estar relacionado ao fato de esse tipo de comportamento ser mais comum na Alemanha como forma de demonstração de interesse e de tornar uma conversa mais interessante, como também aponta Günthner (2008) ao comparar os estilos alemão e chinês. Esse estilo mais confrontativo percebido no comportamento de A2 e em outros momentos no de A3 pode ser relacionado a uma orientação desafiadora da harmonia (rapport challenge orientation), de acordo com Spencer-Oatey (2008, p. 32) e, no modelo 
de Ting-Toomey e Oetzel (2007, p. 127), a um estilo dominador (domination/ competition), mais preocupado com os próprios interesses .

Em contraposição a um estilo mais dominador apresentado pelos alemães, os brasileiros tendem a evitar os conflitos e situações de dissensão, mostrando-se mais harmoniosos. Isso pode ser percebido na entrevista retrospectiva de B2 ao comentar a atitude confrontativa de A2: "a vontade que eu tive de responder foi... porque eu tô fazendo não é problema seu, então você não tem nada a ver com isso. Mas eu fui e dei uma resposta (...) porque num era ambiente para grosseria". Esse comentário mostra que houve da parte de B2 uma preocupação com a harmonia na interação, o que o leva a evitar a expressão direta dos seus pensamentos, não atacando a face do outro. A tendência à harmonização também pode ser percebida no comportamento de B1, que procura concordar com os demais participantes, ainda que parcialmente, ou estabelecer pontos em comum. Essa tendência parece se repetir entre os brasileiros mesmo no caso de B4, que apresenta um estilo mais argumentativo. Em sua entrevista retrospectiva, ele relata alguns momentos em que não concordava com as afirmaçōes, mas que preferiu não se manifestar. Esse comportamento poderia ser relacionado a uma evitação de conflitos (avoiding style) de acordo com o modelo de Ting-Toomey e Oetzel (2007, p. 127).

Nas entrevistas retrospectivas, o único brasileiro que declarou ter se sentido totalmente à vontade foi $\mathrm{B} 1$, um dos participantes mais ativos durante a interação. No geral, os alemães deram um retorno muito mais positivo do que os brasileiros, no sentido de terem se sentido à vontade durante a gravação e na forma como perceberam os brasileiros, caracterizando-os no máximo como "tímidos". Todavia, a divergência entre o que foi dito explicitamente na conversa e aquilo que foi comentado nas entrevistas retrospectivas é maior no caso brasileiro. Embora durante a interação os brasileiros não tenham se manifestado nesse sentido, nas entrevistas retrospectivas revelaram pontos de dissensão ou críticas em relação ao que havia sido dito pelos alemães e às suas atitudes, referindo-se a elas em alguns momentos como esnobes ou indelicadas. Essa característica se mostra consonante com os resultados do estudo de House (2003), que atribui um estilo mais direto aos alemães e com os resultados de Carvalho e Trevisan (2003), que apontam para um estilo comunicativo mais indireto dos brasileiros, principalmente no que concerne a respostas negativas: "Não se confronta, não diz não, mesmo quando discorda" (CARVALHO; TREVISAN, 2003, p. 82-83). 
É interessante observar que o participante A2 mostra uma atitude altamente reflexiva durante a conversa, oscilando entre uma perspectiva comunicativa e extracomunicativa ${ }^{6}$ e comentando os resultados da sua reflexão em público. Isso pode provocar uma recepção negativa nos outros participantes, uma vez que o fluxo da conversa é constantemente interrompido e questionado, contribuindo para que a atitude de A2 seja vista como provocativa. Ele não apenas assume o papel do moderador, mas também comenta constantemente as enunciaçôes dos outros, como ocorre em outro momento, enquanto A1 estava falando e $\mathrm{A} 2 \mathrm{o}$ interrompe comentando o sotaque alemão de A1, dizendo que ele o considera muito bonito. Uma atitude semelhante pode ser observada no trecho seguinte, em que B4 pergunta a B3 o que gosta de fazer no tempo livre:

01 B4: então. (-)

02 tempo livre.

$03 \quad(1.0)$

04 B4: B3.

05 A2: é,= fala alguma coisa $[(\mathrm{xxx})]$

06 A4: [fala ] meu filho,

$07 \quad$ (bate nas costas de B3))

08 A2: ((ri))

09 B1: falar no tempo livre-=né?

10 B3: não:

$11 \quad(-)$

12 ah eu gosto de sair ouvir música-

$13 \quad(1.0)$

14 B3: ah:

$15 \quad(1.1)$

16 B3: coisa normal-(.)

17 (aí) eu não tenho muito o que falar não.

$18 \quad(1.1)$

19 B4: principalmente em belo horizonte-=né?

20 não tem muita coisa pra fazer no tempo livre,=né?

21 B3: ah não bleu acho beagá muito boa.

22 A2: isso é outra coisa quel ((abana a cabeça))

23 B3: nó eu acho que [beagá tem muita coisa pra fazer.] 
24 B1: [tem $(\mathrm{xxx})$ tem pra caramba também;]

25 A2: pois É.

26 olha só olha só. (.)

27 não tem nenhum daqui (.) não tem ninguém de beagá-

28 <<alterando a voz> beagá é uma grande roça.>

29 (.) bh não tem nada pra fazer;=

30 [=porque que todo mineiro-]

31 B3: [nó não tem nada mais $(\mathrm{xxx})$ ]

32 A2: porque que gente daqui fala isso?

33 A1: $(\mathrm{xxx})$ MENTIRA. $=$

$34=$ =você tem tanta instituiçōes culturais aqui;

35 você vê palácio dos artes,

36 tem um monte de galerias,

37 de museus, (.)

38 você tem ololo a lallagoa de pampulha que é cheio sempre qul de de exposiçōes (mudando)

No momento em que B4 faz o comentário sobre a falta de oportunidades em Belo Horizonte, A2 já começa a abanar a cabeça (linha 22) exprimindo, por esse gesto, sua dissensão em relação ao conteúdo do comentário. Quando B3 discorda de B4, dizendo que considera a cidade boa (linhas 21 e 23), A2 inicia uma grande argumentação sobre este estereótipo colocado, segundo ele, sempre por mineiros sobre sua própria cidade que ele, em concordância com B3, considera bastante interessante para atividades no tempo livre. Durante toda essa excursão, A2 dirige-se a B4 por meio de uma estratégia 'polidez negativa' através do afastamento pessoal (personal withdrawal), que desfocaliza o interlocutor, dirigindo a dissensão às convicções do mesmo. (cf. MEIRELES, 2002, p. 111; 1997, p. 174).

Uma estratégia utilizada por alguns participantes durante a interação é o uso de expressões corporais ou faciais para demonstrar a divergência de opiniōes sem que se recorra à expressão verbal da dissensão. $\mathrm{O}$ uso dos gestos se mostra uma estratégia recorrente ao longo da conversa para a expressão da dissensão. Por um lado, esses gestos poderiam ser vistos em alguns casos como uma forma de expressão 'bald on record da dissensão, uma vez que mostram iconicamente de forma clara a posição do participante. Por outro lado, o fato de essa expressão não ser realizada verbalmente faz com que ela possa ser classificada como uma 
estratégia 'off record', já que utiliza meios indiretos para a realização do FTA. A teoria de Brown e Levinson (1987) não permite uma definição clara de qual seria a estratégia utilizada nesse caso.

Os meios não verbais como entonação e prosódia também assumem um papel importante para a expressão de dissensão. Foi observado durante a interação, de forma recorrente, a opção pela estratégia 'bald on record por parte dos brasileiros, sem nenhuma marcação verbal que denote o uso de polidez e que, no entanto, não parece causar conflito ou desconforto algum aos participantes. Essa observação também se opõe às afirmações de Brown e Levinson (1987) que veem essa alternativa como a mais invasiva. O que ocorre no caso brasileiro é que as ameaças à face, embora sejam expressas de forma direta, são amenizadas por 'pistas de contextualização' (Gumperz, 1982) como a altura da voz, a entonação ou mesmo o tom melodioso com que algumas vezes são enunciadas, como mostra o trecho seguinte:

01 A3: então você fala japonês de verdade?

02 B2: ((com mão na nuca)) ohh

03 <<afirmando com a cabeça> é::>

04 A3: não porque: japonês é uma: ah: das línguas mais difíceis do mundo:-

05 B2: $\uparrow \mathrm{NÃO}$,=não é:;

06 A3: não é?

A presença da prosódia característica na fala de B2 (linha 05) poderia equivaler para os brasileiros a uma estratégia de polidez negativa, uma vez que minimiza a imposição do FTA, tornando-o mais ameno, ou mesmo a uma estratégia de polidez positiva, já que o tom de voz mais harmonioso poderia indicar uma atitude amigável em relação ao interlocutor. $\mathrm{O}$ fato de esses aspectos não verbais não serem abordados por Brown e Levinson (1987) porém, mostra uma lacuna na teoria e se reflete em problemas de classificação dos FTAs. De qualquer forma, o efeito causado pelos elementos não verbais na fala dos brasileiros, juntamente com outros aspectos verbais, parece apontar para uma tendência à harmonização e à concordância com o outro, como se vê em outros trechos ao longo da interação. Nos termos de Spencer-Oatey (2008, p. 32), pode-se falar de uma orientação por uma elevação da harmonia (rapport enhancement orientation), o que pode ser observado de forma bastante clara no trecho seguinte, no qual B1 responde à pergunta sobre onde ele gostaria de morar: 
01 B1: ah;

$02(-)$

03 lugar que eu por exemplo eu conheci;

$04 \quad(-)$

05 B1: e achei MUIto bonito qualidade de vida Ótima:- (.)

06 buenos aires.

07 A3: AH:-

08 B1: custo de vida lá [embaixo,]

09 A3: [odeio;]

10 B1: cidade LIN:da,

$11 \quad(-)$

12 A3: fiquei lá quatro\ [quatro semanas;

13 B1: [lá é maravilhO:so.]

14 A3: odeio.

15 B1: lá é pra passarl

16 A3: só tem cocô lá:-

17 ((mostra o chão com as palmas abertas))

$18 \quad(\mathrm{xxx})$ cocô de cachorros (.) ahn lá na ru:a.

$19 \quad(-)$

20 B4: só merda de cachorro,

21 A3: você só precisa desvia:r lá-

22 B1: hahaha

23 A1: buenos aires?

24 B1: buenos aires.

25 A3: buenos aires é o/a cidade MAIS-

26 B1: <<p > não não é não->

27 A3: [ah=sujo que eu já vi.]

28 B3: esse é brasileiro. ((aponta para A3))

29 A3: ahn?

30 B3: [esse é brasileiro.]

31 A2: [você num foi] em muita cidade ainda,=né?

32 A3: ah;=mu:itas cidades (.) também na á:frica:,

33 é:=(outras) cidades.

34 muitas [(also)] mais/mais sujo do (sic!) rio,

35 B1: [eu achei-]

36 B1: é mesmo?

37 A3: mais sujo do são paulo-

38 émE:smo.

39 (.) a cidade: sujo demais.

40 B1: <<sorrindo> eu não sei se é porque eu fui lá em lua de mel,>

41 então eu tava com outro clima assim- 


\section{A2: ((ri alto)) \\ $43 \quad$ ((risos))}

44 B4: <<rindo > com certeza foi isso.>

Nesse trecho percebe-se uma contraposição do estilo alemão, mais dominador, e do brasileiro, mais harmônico. Mesmo que o participante B1 demonstre uma opinião contrária (linha 26), sua contradição é expressa de forma menos incisiva, aparentemente não tendo sido notada pelos demais participantes, devido ao volume de voz mais baixo utilizado para expressá-la. Ao mesmo tempo, o participante alemão $\mathrm{A} 3$ insiste em uma opinião contrária à de $\mathrm{B} 1$ utilizando a opção 'bald on record para expressá-la (linha 14). A reação de B1 em seguida é uma relativização da afirmação anterior através de uma justificativa anedótica (linhas 40 e 41), provocando o riso dos outros e reparando a harmonia novamente, o que se mostra uma preocupação recorrente dos brasileiros nessa interação.

\section{Considerações Finais}

A análise de um encontro intercultural entre brasileiros e alemães trouxe à luz alguns resultados que estão em sintonia com outros estudos no campo pragmático voltados para estilos comunicativos de cunho comparativo (HOUSE, 2003; MEIRELES, 2001, 2002 e 2003; SCHRÖDER, 2003 e 2010). Enquanto os alemães buscam aprofundar certos pontos da conversa de modo mais detalhado, pelo menos três dos quatro brasileiros assumem uma atitude mais reservada e menos empolgada. Pode-se resumir que, nos termos de Ting-Toomey e Oetzel (2007, p. 126-129), os participantes brasileiros tendem mais a um estilo interacional de conflito mais preocupado com a face do outro (Concern for Other), o que se manifesta através dos padrões de comportamento Avoiding e Accomodation, ao passo que os participantes alemães estão mais preocupados com a própria face (Concern for Self), apresentando os padrões de comportamento Domination, mas também Integration, visto que um dos interesses demonstrados com um estilo mais incisivo de questionamento seria o aprofundamento da conversa.

Naturalmente não se pretende aqui uma extensão dessas características a brasileiros e alemães de forma generalizada, uma vez que mesmo entre os participantes da interação já foram observadas diferenças significativas. O estilo de dominação, por exemplo, é observado com mais intensidade nos participantes 
A2 e A3. O participante B1 é o que mostra um estilo mais acomodativo e de certo modo colaborativo, enquanto o participante B2 prefere muitas vezes evitar o conflito. Essas diferenças apontam, por um lado, para a existência de uma relatividade cultural relacionada a características individuais e que delineia diferenças observáveis dentro de um mesmo grupo cultural, como foi exposto na seção 1 . Tal relatividade reforça a necessidade de análise de interações interculturais reais, proporcionando uma maior compreensão das diferenças culturais observadas e dos potenciais conflitos decorrentes do contato intercultural. Por outro lado, a relativa heterogeneidade do comportamento dos participantes não exclui a possibilidade de existência de tendências que possivelmente se relacionam com o pano de fundo cultural deles.

Seria interessante também ir um pouco além dessas observações analisando o papel de A2. O estilo direto que este participante demonstra na interação pode ser atribuído tanto a características individuais quanto ao seu pano de fundo cultural. Questiona-se, nesse sentido, se uma estada longa em uma cultura diferente poderia reforçar certas atitudes provenientes da cultura de origem. Sendo ele o participante com maior tempo de permanência no Brasil, é possível que tenha havido um reforço de uma característica considerada 'alemã' e que pode ser percebida como divergente da cultura brasileira. Um indício dessa influência da longa permanência na cultura alheia seria o estilo de fala altamente reflexivo $^{7}$ que ele demonstra durante a conversa, como vimos na seção anterior.

Ademais, não basta interpretar os resultados meramente pela dicotomia 'direto-indireto', visto que se revelaram aspectos que apontam a necessidade de uma descrição mais situacional: por um lado, as expressões de dissensão pelos participantes brasileiros, em alguns momentos, são muito mais diretas do que as dos alemães, por não fazerem uso de estratégias de polidez; por outro lado, essa escolha não aparenta causar constrangimento ao interlocutor, sendo ele brasileiro ou alemão. Nessa perspectiva, poderíamos pensar que não é necessariamente o tom direto que assusta, mas, sim, a intenção inferida com base na manifestação linguística da dissensão. Dessa forma, as estratégias utilizadas são interpretadas de acordo com a respectiva teoria individual sobre o mundo, podendo ganhar diferentes significados. No caso de um enunciado que exprimisse uma crítica ao Brasil, por exemplo, uma interpretação possível seria voltada para o conteúdo do que foi proferido, enquanto outra poderia se estabelecer no nível relacional, supondo-se uma intenção de minorizar ou desafiar o outro. 
Nesse sentido, pode-se dizer que a teoria de Brown e Levinson (1987), ao não levar em conta os aspectos interpessoais e situacionais de uma interação seria muito idealizada. Isso pode ser percebido na dificuldade de aplicação da teoria a situações concretas, como foi mostrado nas diferentes possibilidades de interpretação das perguntas de $\mathrm{A} 2$ como perguntas de fato (o que representaria uma estratégia 'on record polidez positiva') ou como perguntas retóricas (implicando a estratégia 'off record'), entre outras situaçōes. Além disso, a teoria não considera a diversidade cultural dos padrões comunicativos, mostrando-se categórica ao apontar certas estratégias como mais/menos apropriadas a determinadas situações. Como discutimos na seção anterior, nem sempre uma estratégia considerada como 'muito direta' ou mesmo 'rude', no caso da categoria 'bald on record', será interpretada como tal, enquanto categorias consideradas mais atenuadas, como a 'off record', podem causar um maior dano à face através do uso de ironias, insinuaçōes e perguntas retóricas.

Naturalmente o contexto da interação é de suma importância para a análise e dele dependem as interpretaçóes e escolha das estratégias e estilos a serem usados. Quando se comparam os padróes comunicativos alemães e brasileiros, a dicotomia 'direto' e 'indireto' pode se inverter dependendo do contexto interacional. Em uma situação de compra, de telefonema ou em conversas entre professor e aluno, por exemplo, os padrōes brasileiros já parecem muito mais diretos ou invasivos em oposição aos alemães, como foi mostrado por Schröder (2011). Isso apontaria a influência que o gênero comunicativo, além dos outros aspectos já mencionados nesta seção, pode exercer sobre as decisōes do falante para produzir ou interpretar determinado enunciado, prescrevendo certas formas de comportamento verbal e não verbal. Dessa forma, a diferença de comportamento observada pelos participantes brasileiros e alemães poderia também advir das suas diferentes concepçôes do gênero comunicativo 'conversa estimulada' e dos padrões comunicativos que esse gênero envolve. Como resume B2, "num era um ambiente para grosseria". 


\section{Notas}

${ }^{1}$ Mestre em Estudos Linguísticos pela UFMG.

${ }^{2} \mathrm{O}$ projeto insere-se no GIEL - Grupo Interinstitucional de Estudos de Lingua(gem): usos, contatos e fronteiras, e, dentro dele, na linha de pesquisa 'Pragmática Intercultural'.

${ }^{3}$ Ilustração de autoria de Mariana Carneiro Mendes

${ }^{4} \mathrm{~A}$ transcrição da interação foi realizada em conjunto pelos alunos participantes do grupo de pesquisa sob a coordenação de Carolina de Viterbo Lage.

${ }^{5}$ Como a participação de alemães e brasileiros na interação foi hetereogênea, os números percentuais apresentados nessa tabela referem-se a cada instância de realização de discordância em relação à sua classificação. Assim, na primeira linha, por exemplo, 10,81\% representa o número de realizaçōes do tipo Off record nas 37 discordâncias observadas entre alemães.

${ }^{6}$ Uma análise da tendência alta à metarreflexão na fala cotidiana entre alemães encontra-se em Schröder (2004). Enquanto a perspectiva extracomunicativa se refere à visão do (autor) observador que categoriza as unidades observadas de fora, a perspectiva comunicativa refere-se ao envolvimento no processo comunicativo perguntando como indivíduos põem e manejam a língua na comunicação atual, o que significa para eles colocar uma enunciação em uma situação dada e como eles realizam o entendimento de um enunciado colocado pelo outro. Para Ungeheuer, que estabeleceu essa diferença principal nos anos sessenta, foi importante a exigência de uma Ciência da Comunicação que fizesse, além de uma abordagem extracomunicativa, predominante naquela época, questões com base em uma perspectiva comunicativa e funcionalista (UNGEHEUER, 1972).

${ }^{7}$ Veja também o artigo clássico sobre este fenômeno do sócio-filósofo Alfred Schütz (1944).

\section{Referências}

BROWN, P.; LEVINSON, S. Politeness: Some Universals in Language Usage. Cambridge: Cambridge University Press, 1987.

CARVALHO, M. G.; TREVISAN, L. Relaçōes interculturais entre trabalhadores brasileiros e alemães na VW-Audi de S. José dos Pinhais. Revista Educação \& Tecnologia, v. 7, p. 68-86, 2003. 
CLYNE, M. Inter-cultural communication at work: cultural values in discourse. Cambridge: Cambridge University Press, 1994.

DIONÍSIO, A. P. Análise da Conversação. In: MUSSALIM, F.; BENTES, A. C. Introdução à Lingüistica 2. Domínios e Fronteiras. São Paulo: Cortez, 2006. p. 69-99.

GOFFMAN, E. Interaction Ritual: Essays on Face-to-Face Behavior. New York: Pantheon Books, 1967.

GRICE, H. P. Logic and conversation. In: COLE, P.; MORGAN, J. L. Syntax and semantics. New York: Academic Press, 1975. 41-58.

GUMPERZ, J. Discourse strategies. Cambridge: Cambridge University Press, 1982.

GÜNTHNER, S. Negotiating Rapport in German-Chinese Conversation. In: SPENCEROATEY, H. Culturally Speaking. Culture, Communication and Politeness Theory. London: Continuum, 2008. p. 207-226.

HOUSE, J. Misunderstanding in intercultural university encounters. In: HOUSE, J.; KASPER, G.; ROSS, S. Misunderstanding in Social Life. Discourse Approaches to problematic Talk. London: Longman, 2003. p. 22-56.

KASPER, G. Data Collection in Pragmatics Research. In: SPENCER-OATEY, H. Culturally Speaking. Culture, Communication and Politeness Theory. London: Continuum, 2008. p. 279-303.

MARKOWSKY, R.; THOMAS, A. Studienhalber in Deutschland. Interkulturelles Orientierungstraining für amerikanische Studenten, Schüler und Praktikanten. Heidelberg: Asanger, 1995.

MEIBAUER, J. Pragmatik. Tübingen: Stauffenburg, 2008.

MEIRELES, S. M. Dissens und Höflichkeit - Deutscher Diskussionsstil aus einer fremden Perspektive. Pandaemonium Germanicum, v. 7, p. 215-233, 2003.

MEIRELES, S. M. Dissension and Face-work Strategies in German Dialogues. Tübingen: Max Niemeyer Verlag, 2002.

MEIRELES, S. M. A negação sintática em diálogos do alemão e do português do Brasil. Pandaemonium Germanicum, v. 5, p. 139-168, 2001.

MEIRELES, S. M. A dissensão e as estratégias de trabalho da face em diálogos do alemão. 1997. Dissertação (Doutorado em Letras) - Faculdade de Filosofia, Letras e Ciências Humanas, Universidade de São Paulo, São Paulo, 1997.

PIZZICONI, B. Politeness. In: MEY, J. L. (Ed.). Concise Encyclopedia of Pragmatics. Oxford: Elsevier, 2009. p. 706-710. 
SCHRÖDER, U. Pragmática Intercultural. In: BOHUNOVSKY, R. Ensinar alemão no Brasil: contextos e conteúdos. Curitiba: Editora UFPR, 2011. p. 147-170.

SCHRÖDER, U. Speech styles and functions of speech from a cross-cultural perspective. Journal of Pragmatics, v. 42, p. 466-476, 2010.

SCHRÖDER, U. Comunicação Intercultural: uma desconstrução e reconstrução de um termo inflacionário. Cadernos de Linguagem e Sociedade, v. 9, p. 38-49, 2008.

SCHRÖDER, U. Der Selbstbeobachter - ein deutsches Phänomen? Selbstreflexionsprozesse und ihre kulturspezifische Ausprägung. Kodikas Code Ars Semeiotica, v. 27, p. 41-58, 2004.

SCHRÖDER, U. Brasilianische und deutsche Wirklichkeiten. Eine vergleichende Fallstudie zu kommunikativ erzeugten Sinnwelten. Wiesbaden: Deutscher Universitätsverlag, 2003.

SCHÜTZ, A. The Stranger: an Essay in Social Psychology. The American Journal of Sociology, v. XLIX, n. 6, 5, p. 499-507, 1944.

SELTING, M.; AUER, P.; BARTH-WEINGARTEN, D. Gesprächsanalytisches Transkriptionssystem 2 (GAT 2). Gesprächsforschung - Online-Zeitschrift zur verbalen Interaktion, n. 10, p. 353-402, 2009.

SPENCER-OATEY, H. Face, (Im)Politeness and Rapport. In: SPENCER-OATEY, H. Culturally Speaking. Culture, Communication and Politeness Theory. London: Continuum, 2008. p. 11-47.

TING-TOOMEY, S.; OETZEL, J. Intercultural Conflict: A Culture-Based Situational Model. In: COOPER, P. J.; CALLOWAY-THOMAS, C.; SIMONDS, C. J. Intercultural Communication. A Text with Readings. Boston: Pearson Education, 2007. p. $121-130$

UNGEHEUER, G. Kommunikative und extrakommunikative Betrachtungsweisen in der Phonetik. In: UNGEHEUER, G. Sprache und Kommunikation. Münster: Nodus Publikationen, 1972. p. 22-34.

UNGEHEUER, G. Vor-Urteile über Sprechen, Mitteilen, Verstehen. In: UNGEHEUER, G. Ungeheuer Kommunikationstheoretische Schriften I: Sprechen, Mitteilen, Verstehen. Aachen: Rader Publikationen, 1987. p. 290-338.

WIERZBICKA, A. Cross-cultural pragmatics: the Semantic of Human Interaction. 2. ed. Berlim: Walter de Gruyter, 2003. 


\section{ANEXO}

Convenções de transcrição GAT-2 utilizadas nos trechos deste artigo (Convenções selecionadas e traduzidas livremente de Selting, Auer, Barth-Weingarten et al., 2009)

\section{Símbolo Significado}

[]

[] Fala simultânea

= Anexação de nova unidade de fala de forma rápida, imperceptível

(.) Micropausa menor que $0.25 \mathrm{~s}$

(-), (--), (--) Pausas de cerca de respectivamente $0.25,0.75$ e até $1 \mathrm{~s}$. Pausa estimada

:, ::, :: $\quad$ Prolongamento de sons, de acordo com duração

((ri)) Acontecimentos não verbais e paralinguísticos pontuais

$<<$ rindo $>>$ Acontecimentos não verbais e paralinguísticos com alcance

$<<$ p $>>\quad$ Piano, fala em volume de voz mais baixo

aCENto Acento primário ou principal

? Entonação no fim de unidades alto-ascendente

, Entonação no fim de unidades médio-ascendente

- $\quad$ Entonação no fim de unidades inalterada

; $\quad$ Entonação no fim de unidades médio-descendente

- Entonação no fim de unidades baixo-descendente

$\uparrow \quad$ Movimento tonal para cima

$\wedge$ SO Movimento tonal ascendente-descendente

oh, ohh, ohhh Inspirações, de acordo com duração

(xxx xxx) Passagem incompreensível, sendo cada xxx equivalente a uma sílaba

(algum) Palavra suposta 